Outros Textos 


\title{
CRÍTICA DA RAZÃO CULTURAL GUINEENSE: UM ESTUDO SOBRE A REPRESENTAÇÃO DA CULTURA EM KIKIA MATCHO, TEXTO FICCIONAL DE FILINTO DE BARROS
}

\author{
CRITICISM OF GUINEAN CULTURAL REASON: A \\ STUDY ON THE REPRESENTATION OF THE CULTURE \\ IN KIKIA MATCHO, FICTIONAL TEXT OF FILINTO DE \\ BARROS
}

Sebastião Marques Cardoso*

Resumo: Kikia Matcho (1997), obra de ficção de Filinto de Barros [1942-2011], merece uma releitura por vários motivos: a)- porque, em face de sua historicidade, o livro é publicado num momento delicado da vida política nacional guineense; b)- porque a sua existência é também reveladora dentro do cânone da literatura pós-colonial de língua portuguesa; c)- porque ainda o livro, enquanto artefato puramente estético, apresenta características peculiares e d)- porque, fundamentalmente, a obra traz de maneira tensa e contraditória vários modos de representação da cultura guineense. Pensando nisso, vamos, neste artigo, tratar, numa primeira etapa, dos três primeiros elementos, conscientes, entretanto, da brevidade da análise e de que os respectivos assuntos poderiam ser ampliados e desenvolvidos em análises separadas. Mesmo assim, justificamos a presença da primeira etapa em nosso texto como, sobretudo, introdução e contextualização da obra de Filinto de Barros para que, na segunda etapa, momento este em que vamos discutir a questão da representação cultural guineense, não percamos de vista o tempo e a complexidade literária da obra deste autor negro-africano.

Palavras-chave: teoria literária, estudos pós-coloniais, literaturas africanas de língua portuguesa, Filinto de Barros

* Professor Teoria da Literatura do Departamento de Letras Estrangeiras, da Universidade do Estado do Rio Grande do Norte (UERN). 


\begin{abstract}
Kikia Matcho (1997), fiction work by Filinto de Barros [1942-2011], deserves a rereading for various reasons: a) - because, in the light of its historicity, the book was published under a delicate moment of Guinean national political life; B) - because its existence is also some revealing within the canon of post-colonial literature in Portuguese language; C) - because the book yet, as a purely aesthetic artifact, presents peculiar characteristics and d) - because, fundamentally, the work brings in a tense and contradictory way several manners of representation of Guinean culture. With this in mind, we are going to deal, in this work, in a first stage, about the first three elements, however, aware of the brevity of the analysis and that the respective subjects could be expanded and carried out in separate analyzes. Even so, we justify the presence of the first stage in our writing as, above all, introduction and contextualization of the work of Filinto de Barros so that, in the second stage, the time when we will to discuss the matter of Guinean cultural representation, we do not lose sight of the time and the literary complexity of the work of this black African author.

Keywords: literary theory, postcolonial studies, African literature in Portuguese language, Filinto de Barros
\end{abstract}




\section{Da historicidade e recepção}

Kikia Matcho é um livro de ficção, escrito pelo guineense Filinto de Barros [1942-2011], publicado pelo Instituto Camões em Guiné-Bissau, no ano de 1997. Nesse período, o país da costa ocidental africana enfrenta grandes dificuldades para manter a estabilidade econômica, social e política: a sociedade guineense não consegue concretizar um acordo de união nacional. Além disso, o descontentamento da população com a ordem política que se estabeleceu desde o fim da luta armada chegava ao ápice, haja vista que muitos dos ex-combatentes se viram marginalizados no processo de nacionalização do país e, por consequência, passaram a se sentir traídos e abandonados por dirigentes políticos que, antes, foram inclusive companheiros de luta em variadas frentes contra os portugueses.

Na edição elaborada pela Editora Caminho (1999), o livro traz o subtítulo "O desalento do combatente", o que reforça a perspectiva adotada pelo autor. Embora o livro não trate diretamente da guerra de libertação, a focalização é, majoritariamente, de ex-combatentes guineenses que, mesmo tendo servido em campos opostos na luta, vivem, tempos depois, em espaços sociais degradados da cidade de Bissau. Todos ex-combatentes, tais como Farim, Papai, Gala e Tocaviolas experimentam o desalento, ou seja, a percepção de que a independência não resultou em dias melhores e que, agora, vivem como miseráveis na cidade, dependendo das minguadas pensões de guerra e de sopas compradas a crédito.

Contrastando com a geração de ex-combatentes, aparecem duas figuras emblemáticas, representando a nova geração de guineenses, daqueles que cresceram no tempo da independência. Trata-se de Joana e de Benaf, ambos os sobrinhos de 'N Digui, um ex-combatente cuja morte suscita uma série de complicações dentro da narrativa. Representantes da nova geração guineense, Joana e Benaf, apesar de adotar atitudes diferentes entre si, já não compartem da mesma visão da geração anterior e, dentro do contexto em que vivem, buscam melhores condições de vida em espaços distintos e de diferentes maneiras. Com a inserção desses novos personagens, Kikia Matcho tenta mostrar, de forma dinâmica, como foi o desdobramento da sociedade guineense no período curto de paz do pós-guerra, que foi de 1973 (fim da guerra colonial) até a data presente do livro, 1997. Nos dois anos seguintes (1998/1999), o país experimentará a guerra civil, infelizmente. 
Do ponto de vista histórico, o livro de Filinto de Barros foi, assim, um diagnóstico da situação social e política da Guiné-Bissau cujo desenlace surpreendentemente se fez sentir no futuro próximo. Toda a atmosfera negativa da narrativa, na imagem de uma coruja macho, o kikia matcho na língua crioula de Bissau, parece se confirmar no destino guineense. Mesmo após a guerra civil, o país, levando em conta os índices econômicos e sociais medíocres, continua mergulhado em tensões e conflitos políticos de alta octanagem. Nesse sentido, cremos que a obra do escritor guineense, apesar de presa a um contexto histórico específico, pode oferecer suplementarmente uma compreensão do estágio mental guineense para além do horizonte histórico em que ela nasceu.

A verossimilhança entre os fatos narrados e a sua relação com o período histórico vivido pelos personagens a partir do episódio de Pindjiguit (1959) até a primeira década da pós-colonização estão bem delineadas no livro, pois Filinto de Barros adota um narrador externo à história (até certo ponto, como veremos mais adiante), o que facilita na tomada e na transposição de vários planos espaciais e temporais dentro da narrativa. O narrador pode, por exemplo, contar a história de Joana em Portugal e também narrar, ao mesmo tempo, a presença de Benaf em Bissau.

Contudo, esse narrador não se comporta como um narrador clássico em terceira pessoa: além da função prática de atribuir voz aos personagens para que o auxilie na informação e descrição sobre o cenário literário, ele interpreta e firma sua posição/visão sobre os acontecimentos. Essa atitude do narrador o aproxima do narrador-testemunha, daquele que, com sua visão limitada, afirma sua subjetividade diante daquilo que ele próprio está a descrever. Ora, para além das problematizações com a teoria literária, entendemos que o narrador de $\mathrm{Ki}$ kia Macho espelha, na verdade, a mundivivência do próprio autor. O narrador funciona, para Filinto de Barros, não apenas como um mecanismo narrativo para organizar e contar a história, mas, ainda, como "alguém" que, ao recuperar a história, imprime uma revisão sobre ela.

Agora, podemos nos perguntar, por que essa revisão poderá corresponder à mesma visão do autor? A resposta pode ser encontrada na biografia do autor. $\mathrm{O}$ campo de visão do narrador compreende exatamente o campo de experiência do autor. Filinto de Barros foi combatente na luta de libertação, fez parte, por um período, do governo, exercendo ainda a função de embaixador em Portugal. Portanto, Filinto de Barros conheceu muito bem a realidade da luta de liberta- 
ção, a realidade da política pós-colonial que veio depois e, ainda, a situação dos guineenses em Portugal quando, na ocasião, foi embaixador da Guiné-Bissau. Toda essa trajetória de vida parece estar diluída na narrativa, por meio, sobretudo, das variadas correspondências, diálogos e complicações diversas entre personagens e paisagens que compõem o livro.

Isso posto, acreditamos que Filinto de Barros apresentou um painel, por meio da ficção, da transformação "sócio-cultural de um Povo" que, para ele (e seu Outro, o narrador), se distancia do rigor de uma análise de cunho puramente histórico, sociológico ou político. O regime do texto literário aceita o contraditório, o confuso e também o interdito. Sua primazia está para além da conformação do discurso lógico-matemático ou científico, pois opera por meio de imagens e percepções diversas. De modo que o regime a obra pode absorver e resolver a própria expectativa do autor que a fez vir a público. Entretanto, como um homem inscrito na própria temporalidade da obra, Filinto de Barros quis compreender esse "processo de síntese sócio-cultural" por um ângulo que lhe escapava, ou seja, por sua ideologia científica e política. Essa presunção foi, inclusive, observada por Moema Parente Augel (1998, p. 373): “/.../ os comentários que [o narrador] exprime [acerca dos agouros do Kikia] são sobretudo de ceticismo, dando a impressão como se o intelectual de formação marxista e materialista não pudesse aceitar tais fraquezas ou ingenuidades, não disfarçando seu distanciamento".

Paradoxalmente, a sua formação marxista, bem como a sua experiência no espaço pós-colonial, materializaram a perspectiva do autor africano num duplo que se encaixa na obra como matéria de ficção tanto quanto aqueles homens e mulheres guineenses que the serviram de modelos aos seus personagens. Isso significa, então, que Filinto de Barros é também um elemento narrativo representado na obra em que, diferentemente de outros personagens, é objeto/problema e ao mesmo tempo sujeito/problema desse "processo de síntese sócio-cultural".

Enfim, supomos que o autor/narrador expressa tanto o desajuste com a perspectiva logocêntrica de base marxista na compreensão dos elementos quanto a sua intuição (guineidade revelada?) em relação ao mundo imaterial, irreversível e transformador das coisas que estão a agir. Portanto, esse mundo não cognoscível no momento da enunciação, mas sensível, pois vivido e experimentado, aparece assim na forma de um grande enigma a ser desvendado, ou seja, na ima- 
gem de um "kikia matcho". É na representação da coruja, e não na especulação racional do tempo histórico, que o sentido da História poderá ser recuperado aos próprios guineenses. Em síntese, com a inscrição do enigma, o livro dá pistas de compreensão àquilo que o autor, em seu tempo, não foi capaz de desvendar.

\section{Do cânone da literatura africana pós-colonial}

A literatura pós-colonial de língua portuguesa está inscrita no universo das literaturas africanas pós-coloniais produzidas pelos PALOP - Países Africanos de Língua Oficial Portuguesa - , com exceção de Timor-Leste e Macau (HAMILTON, 1999). Nas sequências de ex-colônias que se constituíram em grandes nações, como a Nigéria e a África do Sul, por exemplo, uma cultura literária em África vinha se desenvolvendo desde os tempos coloniais e, no período pós-colonial, essa literatura atingiu o seu ápice, tendendo, sobretudo, ao questionamento dos valores ocidentais e à reflexão crítica mais densa sobre a contemporaneidade da cultura africana na era pós-colonial.

Nos espaços coloniais de língua portuguesa, no entanto, a atividade literária foi reduzida, se comparamos às manifestações em língua inglesa ou francesa, mas, por outro lado, teve igualmente impacto sobre os anseios da nova classe política dos países recém-libertos, na esperança, sobretudo, de garantir uma unidade política nacional, mínima que fosse, por meio de um programa literário que servisse de campo ideológico de uma síntese de valores obtidos pela experiência da guerra de libertação.

Nesse sentido, os autores de língua portuguesa que se destacaram na literatura pós-colonial são, sobretudo, autores que, de algum modo, apresentaram algum tipo de vínculo com a luta de libertação. São autores também que, mesmo após a luta, mantiveram laços, por muitas vezes ambíguos e contraditórios, com a nova realidade social e política estabelecida. De modo que, quando analisamos as literaturas africanas pós-coloniais, no seu conjunto, notamos mais semelhanças do que diferenças entre si, ainda que nascidas em espaços africanos pós-coloniais, por meio de conflitos entre culturas autóctones diversas frente a empresas imperialistas historicamente diferenciadas.

Para além do engajamento dos autores na campanha de um 'desorientalismo" no discurso, em contraposição ao "orientalismo" denunciado por Edward 
Said (2007), notamos que aquilo que mais os aproxima não é tanto a primazia do discurso que profetizam, mas as relações tensas desse discurso com a sua própria posição diante do horizonte cultural e político que vivenciam, ou seja, diante do "local" de suas enunciações. Cremos que os escritores africanos pós-coloniais partem de um "lócus" vivido onde as certezas são postas em dúvida, onde a tradição flutua, onde a língua ressignifica e onde o imprevisível se acena. (BHABHA, 1998; GLISSANT, 2005).

Assim, entendemos que o escritor e sua literatura são extensões de uma relação de conflito com o próprio ambiente cultural. E uma análise que deseja captar ou refletir sobre a representatividade literária ficaria incompleta, a nosso ver, se não incluirmos nela as tensões e angústias dos autores circunscritos num espaço político e cultural absolutamente ambíguo e fraturado que, resumidamente, caracteriza a contemporaneidade das nações africanas pós-coloniais. Kikia Matcho e Filinto de Barros, ambos, obra e autor, fazem referência a esse contexto pós-colonial africano, mas na particularidade da realidade política, social e cultural da Guiné-Bissau.

\section{Da particularidade estética}

Kikia Matcho é um romance? Difícil definir o livro de ficção de Filinto de Barros dentro de uma classificação tácita no âmbito da Teoria da Literatura. Se considerarmos a convergência de tensões dentro da narrativa, veremos que o livro se organiza frente a uma única tensão: que é a conversa entre o falecido ' $N$ Dingui com o personagem Papai. Do início ao fim do livro, toda a série de acontecimentos tem como orientação principal levar o enredo a esse ponto culminante do texto. Mesmo as histórias paralelas que se apresentam na narrativa têm esse propósito, pois elas vêm sempre amarradas pela aparição da figura enigmática da coruja macho, associada alegoricamente às necessidades rituais do funeral de 'N Dingui, o personagem mais importante do livro (seguido de Papai, Joana e Benaf).

A presença de 'N Dingui se faz, no início da narrativa, por meio da coruja macho (metamorfose) e das memórias nos mais variados personagens. Contraditoriamente, ' $N$ Dingui é o personagem que mais se expressa na narrativa, mas é, por outro lado, o que menos tem voz textual direta. É a imagem mediada do 
personagem, defunto, que reverbera na figura da coruja, nas lembranças e, por fim, na tomada do corpo de uma jovem na cerimônia fúnebre. O livro começa com o personagem morto e, no decorrer da narrativa, ele sai de sua condição de personagem-defunto para personagem-fantasma. O personagem somente figura como vivo, por meio das memórias de outros personagens, no tempo em que ele era combatente de guerra. Logo, o ex-combatente ' $N$ Dingui constitui no elo mais forte entre a coruja (por vezes sendo ela própria) e demais personagens-vivos do texto. Portanto, ele é o principal ponto de inflexão do passado, do presente e da imagem do futuro da história mental, cultural e psicológica guineense.

Isso posto, entendemos que a narrativa de Filinto de Barros abriga características do conto popular (PROPP, 2006), no que diz respeito sobretudo à condução da narrativa e à caracterização dos personagens. Por isso, os personagens aparecem rasos, pois não foram talhados especificamente para expressarem uma condição psicológica profunda, mas estão arrolados no texto dentro de uma função específica, que é a de impulsionar o enredo e servirem, ao final, de elemento para a compreensão global do texto. Outro aspecto é a sua dimensão fantástica. Entendemos o fantástico aqui como repertório narrativo estranho à explicação racional ou às leis da física. Esse elemento não só atua como novidade na narrativa como é, acima de tudo, sua espinha dorsal, ou seja, funciona como uma porta de entendimento para dizer a realidade, iluminando inclusive os vazios que a racionalidade não é capaz de explicar.

Além disso, Filinto de Barros aproveita a oralidade da língua portuguesa da Guiné-Bissau no seu livro, tornando a narrativa mais fluente, com frases curtas e, em alguns momentos, com vocábulos extraídos diretamente da língua crioula de Bissau. Ora, diante desses aspectos observados (enredo, personagens, elemento fantástico, oralidade e língua), o escritor guineense não usa a narrativa para mostrar o desamparo, por exemplo, de um burguês frustrado ou alienado na sociedade capitalista, por meio de monólogos profundos ou análises psicológicas densas, típicas dos romances contemporâneos. O autor negro-africano, ao contrário, elabora um mosaico literário da sociedade guineense, por meio de uma fina elaboração textual que resulta num quadro dialógico e dinâmico da coletividade, sem perder de vista suas ambiguidades e contradições culturais. 


\section{Da expressão cultural guineense}

Em Kikia Matcho, por conta do contexto (pós)colonial que ressuscita, notamos no narrador e nos personagens principais um conjunto de imagens que caracteriza a arbitrariedade e a duplicidade da identidade cultural em cada um deles. E essas imagens são apresentadas, a nosso ver, em duas dimensões: primeiramente, o livro delineia a dimensão dicotômica da identidade (o que vamos chamar de "primeira dimensão"), construída nas bases da "mímica" e do "estereótipo". Esses termos - mímica e estereótipo - serão vistos a partir de Franz Fanon (2008) e melhor definidos por Bhabha (1998).

Paralelamente, mas num nível mais sensível da interpretação, a própria narrativa põe em questionamento essa natureza arbitrária e maniqueísta da representação (da "primeira dimensão"), oferecendo, em troca, um hibridismo cultural ("segunda dimensão") que vai muito além da perspectiva fechada dos discursos típicos da primeira dimensão. Com isso, tentaremos mostrar, na segunda dimensão, que o livro de Filinto de Barros elabora, sem deixar de ser simplista, um quadro vivo dos conflitos políticos e culturais guineenses. Por essa perspectiva, o livro parece ultrapassar (ou fazer escapar) a genealogia tácita da narrativa histórica da época, sugerindo, assim, uma terceira via para o entendimento da nova configuração da identidade cultural guineense no pós-luta de libertação.

\subsection{A primeira dimensão da representação cultural: estereótipo e mímica}

Se não houvesse um discurso orientalista potente (porque domina as artes da manipulação discursiva e detém a hegemonia dos meios de comunicação), com certeza, os sujeitos locais não se sentiriam tão inclinados a defender e a internalizar a cultura ocidental, ainda que absorvida por meio de fantasias e de esperanças fabricadas. A partilha do discurso ocidental entre os autóctones segue uma orientação econômica, política, militar, religiosa e social de dominação que, resumidamente, abarca pelo menos cinco campos do saber: o do consumo e da técnica (ou epistemológico), o da ideologia, o da segurança, o da edificação moral e religiosa e o da emancipação do sujeito na vida social e cultural.

Em Kikia Matcho, todos os personagens serão afetados pelo discurso orientalista. Entretanto, as relações culturais estabelecidas de aceitação, de hesitação 
e de recusa a esse discurso irão variar de personagem para personagem. Além disso, a situação vivida pelos personagens - num espaço culturalmente entrecortado, habitado tanto pela memória das forças colonizadoras quanto pela ainda apelativa narrativa orientalista de assimilação - irá, por muitas vezes, transcender a própria consciência desses sujeitos representados. Como efeito, a posição ou discurso desses personagens aparecerá por muitas vezes superficial, confuso ou ambíguo, ou seja, fendido quando posto ou comparado à realidade do espaço que habitam.

Para Bhabha (1998), a representação não diz respeito somente ao que pode ou não ser representado, a "realidade" (objeto); a representação do Outro se transforma também em objeto de desejo, o que pode significar ansiedade e conflitos interiores. Por meio desse entendimento teórico, notamos que os personagens Joana e Benaf, por exemplo, procuram realizar-se (ou apagar-se?) na medida em que projetam seus interesses, anseios e desejos na imagem do Outro (no caso, o europeu, agora tido como ex-colonizador e parceiro). Em outras palavras, os personagens veem na imagem do português aquilo que desejam com relação à posição social (no caso de Joana) ou ao reconhecimento intelectual (no caso de Benaf). Vamos, inicialmente, detalhar melhor o comportamento de Joana, depois, trataremos de Benaf.

A experiência in locus de Joana a levará para uma atitude ambígua (que é a de deixar seu país natal), uma vez que seu tio é um remanescente da luta armada de libertação, defensor da cultura guineense e da autonomia política do país. Por outro lado, Joana mostra-se decepcionada com os rumos do país, com a falta de oportunidade na vida profissional. Ademais, ela recebe informações (propagandas?) do antigo país colonizador: "A propaganda dos novos senhores de Belém prometia mundos e fundos aos que renegassem a nova nacionalidade e se declarassem mais portugueses que os portugueses" (BARROS, 1997, p. 24). Portugal, apesar de militarmente reconhecer a derrota em 1974, continua a manter laços profundos com o novo país, por meio sobretudo de instituições e meios diversos de comunicação.

Quando Joana chega a Lisboa, ela tem um deslumbramento, porque se sente realizada diante da confirmação da imagem contrastante entre viver no espaço restritivo de bens de consumo de Bissau a viver na abundância e opulência de Lisboa: "Mas aqui, longe da sua gente, Joana, como tantos outros, alimentava-se da esperança de um dia poder viver como os ricos. Ao menos via a riqueza pas- 
sear ao lado, nos belos automóveis, arranha-céus, bancos e cinemas" (BARROS, 1997, p. 29). Ela agora ocupa o lugar oposto a Bissau e, naturalmente aos negros, o que the rende a sensação de realização pessoal, ainda que momentânea e fruto de uma alienação social e racial. Joana experimenta em si, no seu corpo, a inscrição do branco, esvaziando-se da sua diferença cultural e de sua condição de emigrante.

A experiência dos pobres no alto capitalismo é, para ela, deslumbrante. Estar no meio das mercadorias e dos objetos de desejo significa para ela uma conquista e um avanço social. Contudo, Joana precisa, numa segunda etapa, adquirir pelo menos uma parte desses bens. Só assim, ela estaria mais ou menos integrada à sociedade de consumo que tanto almeja. Por conseguinte, a personagem não demorará a perceber que não basta estar no meio das mercadorias, é preciso ainda ter poder aquisitivo, ou seja, um elemento diferenciador que a separa dos "realmente portugueses". Infelizmente, a trajetória de Joana, como bem observa o narrador, é um fenômeno que assiste a muitos outros guineenses que, frustrados com a nova ordem político-econômica do país, decidem tentar uma vida melhor em terras lusitanas.

A diáspora, por outro lado, levou Joana a refletir melhor sobre sua condição africana e a confrontar o discurso orientalista português com a realidade que encontrou na metrópole. Num lugar apartado da cidade, miserável e insalubre, a personagem se junta a outros deserdados africanos. Aos poucos, a personagem passa a compreender que os africanos são postos na subalternidade e que as diferenças culturais entre mestiços, negros, guineenses e cabo-verdianos pouco importam no contexto da sociedade lisboeta: "Na realidade, a dura existência ensinou-lhe que a cor da pele conta pouco num mundo de desigualdades baseado no poder de compra. Brumedjos, pretos, Guineenses, Cabo-verdianos estavam todos aí, juntos frente ao mundo ocidental, à mercê dos mais ricos" (BARROS, 1997, p. 37).

Na diáspora, Joana constata que para os portugueses todos africanos são negros (sem diferenças entre si) e pobres. A partir desse momento, Joana consolida em si uma dupla consciência: "Aqui precisamos ser portugueses, mas não deixamos de ser negros" (BARROS, 1997, p. 30). Do encanto ao desencanto, Joana se desorientaliza: "Passou pela ponte sobre o Tejo e, em vez de admirar a obra de engenharia, Joana desdenhou a fealdade dos braços compridos de aço abraçando os betões de cimento" (BARROS, 1997, p. 142). 
Ao fim e ao cabo, Joana consegue libertar-se do estereótipo em si, mas não do estereótipo orientado para si, ou seja, a personagem desarma o estereótipo que nela foi internalizado, mas, por outro lado, se sente incapaz de fazer com que o Outro não a tome como um estereótipo. Entendemos aqui o estereótipo para além de uma simplificação da identidade, o estereótipo é, nesse contexto, a figuração da recusa da alteridade, ou seja, "ele nega o jogo da diferença presente no processo relacional da construção da identidade e, com isso, nega a necessidade da alteridade e do hibridismo na construção da identidade" (SOUZA, 2004, p. 123). Bhabha (1998, p. 117) considera o estereótipo como ponto primário de subjetivação no discurso colonial tanto no colonizado quanto no colonizador, acenando como recurso de fantasia e de defesa semelhante.

Se a dupla consciência se revela para Joana, em Benaf, seu primo, a máscara eurocêntrica é cuidadosamente cultivada, passando a ser o principal ponto da referência da imagem do personagem:

Anos de vivência na Europa, anos de prática dum individualismo tacanho, haviamno transformado num ser desumano, num materialista interessado nos sucessos pessoais, saudoso das grandes cidades de luzes por todos os lados, dos automóveis, dos gigantes de betão armado. [...] A África tinha-se esfumado do seu ser (BARROS, 1997, p. 21).

Benaf experimenta, de forma neurótica (FANON, 2008), a despersonalização provocada pelo contexto (pós)colonial, perpetuando a alienação de si e do Outro (identificado como o português): o primeiro por se sentir inferior e o segundo por se sentir superior.

Em Benaf, o estereótipo parece ceder lugar para algo mais invasivo, de modo que toda a identidade do personagem passa a se apresentar como uma "mímica". Entendemos aqui "mímica" como um discurso ambivalente: "[P]ara ser eficaz, a mímica deve produzir continuamente seu deslizamento, seu excesso, sua diferença" (BHABHA, 1998, p.130). A mímica não apenas reproduz de forma excessiva o arquétipo do Outro, mas, sobretudo, exagera na própria expressão cultural do Outro. Trata-se de um processo relacional e dialógico característico da experiência colonial que, no entanto, conduz à erosão das identidades entre colonizador e colonizado. 
Benaf copia, na forma (hábitos, pensamentos, roupas, gostos, etc), a cultura ocidental, pensando em levar vantagem sobre seus próprios conterrâneos. Sob pretexto da morte do tio, ele busca na Guiné reconhecimento, influência e ascensão social: "Voltou porque era africano e intelectual, portanto podia ser ministro ou presidente, mas do continente não conseguia reter nem compreender a profundidade da sua mística" (BARROS, 1997, p. 21). É importante ressaltar que, em Benaf, a consciência dupla existe também, pois Benaf tem consciência de que a "mímica" que faz é um efeito para impressionar e seduzir os guineenses a confiar nele e, por conseguinte, obter legitimidade sobre eles. Trata-se da elaboração consciente de uma fantasmagoria: "O hibridismo do processo de mímica está no fato de que, ao mesmo tempo em que a mímica procura apresentar uma imagem convincente do sujeito, essa mesma imagem denuncia o fato de ser apenas aquilo, uma mera imagem" (SOUZA, 2004, p. 122).

A estratégia de Benaf é, na verdade, uma tática colonialista aplicada de forma dissimulada. Não é mais o branco/europeu que se oferece para administrar o território, mas, agora, é o próprio sujeito local, ansioso por parecer à sua imagem, que se oferece para isso, mostrando-se psicologicamente fraturado, modificado e assimilado à cultura do branco/ocidental. Enfim, o personagem age tendo em perspectiva tanto o olhar do sujeito ocidental quanto o olhar do africano local.

Nesse sentido, Benaf deseja se apresentar como alguém mais capaz, "porque" fala como branco, veste como branco, pensa parecido ao branco e assim por diante. Mas o que melhor resume a reinscrição da posição de branco no negro Benaf é a sua formação. O personagem retorna a Bissau como "Dr.", ou seja, com diploma de curso universitário, o que lhe poderia render uma certa distinção e vantagem sobre seus concorrentes no país. Contudo, um outro personagem ironiza a posição de Benaf, alegando que, de repente, na Guiné recém pós-colonial, o número de doutores aumentou exponencialmente, contradizendo a certeza de sucesso de Benaf: "/.../ Quem não tem filhos ou sobrinhos doutores, pá? Isto hoje está cheio de doutores e engenheiros! Dantes é que era a valer, no tempo dos colon. A gente nem via os doutores, estavam tão longe! Mas hoje, é só dar um pontapé e sai um doutor, pá!" (BARROS, 1997, p. 153).

Isso posto, a posição de Benaf é residual, marcada por uma produção subdesenvolvida do discurso que vem desde o tempo da colonização. 


\subsection{A segunda dimensão da representação cultural: hibridismo e tradução cul- tural}

Vimos, no tópico anterior, como a política da identidade fracassa quando não existe, de fato, uma "relação" (GLISSANT, 2011) entre culturas que habitam um mesmo território. Os produtos culturais que surgem neste contexto carregam, além das típicas ambiguidades, o estereótipo e a mímica como principais características do ponto da imagem da identidade. Essa situação não permite ultrapassagem e, muito menos, uma conciliação cultural entre os diversos atores envolvidos.

Porém, Kikia Matcho expressa também um outro momento entre culturas e identidades, mas vistas, agora, como ponto de viragem. O livro de Filinto tem essa qualidade de pôr em evidência duas narrativas culturais justapostas e, ainda, se reserva em não apontar para nenhuma solução celebratória ou puramente literária. Paralelamente à narrativa colonial/pós-colonial, existe uma outra porta de entendimento acerca da cultura e da identidade, cuja chave de acesso está na não menos explícita imagem do Kikia-a coruja. Diante da imagem elaborada literariamente em Kikia Matcho, vamos agora relacionar a expressão dessa imagem com o fenômeno da hibridização e de seu correlato, que é a tradução cultural.

O espaço pós-colonial se reveste de uma característica bastante peculiar, pois tanto as culturas "de fora" quanto as culturas "de dentro", em face de embates, assimilações e imposições, tremem e flutuam. Isso contribui para um deslizamento de sentidos, instaurando um "terceiro espaço" (BHABHA, 1998), cuja performance não obedece aos imperativos das dicotomias discursivas existentes. Assim, opera-se, no âmbito da cultura, uma forma "rizomática" (DELEUZE; GUATTARI, 1995) ou "compósita" (GLISSANT, 2005) que tem, como rota, a sua ressignificação, independendo das ideologias fechadas do discurso.

O panorama da sociedade guineense pós luta de libertação pode ser resumido como um duplo fracasso: Portugal perde a colônia e, com isso, desperdiça definitivamente a oportunidade de fazer de Guiné-Bissau um território mais ou menos desenvolvido, bem à sua imagem; entrementes, o partido herdeiro da luta pela nacionalização do território (PAIGC) não consegue estabelecer um pacto político duradouro com a nova sociedade guineense, o que tornará Guiné- 
-Bissau um país caótico e sem perspectivas concretas de desenvolvimento econômico e social.

Para o narrador, o tempo da colonização não se difere do tempo "das botas dos tiranos":

A cidade [Bissau], essa, parecia dormitar, mergulhada na escuridão que a falta da lua tornava ainda mais triste. Um cenário normal, num continente que teimava em manter-se no escuro da colonização, do tráfico dos escravos, escuro das independências sob as botas dos tiranos, escuro do analfabetismo, do medo do Além, escuro da fome, da miséria... Escuro como a cor da pele da maioria de seus habitantes!. (BARROS, 1997, p. 15).

A "escuridão" da história do país se estende à "escuridão" de seus habitantes, sendo a cor da pele uma metonímia para dizer a invisibilidade do sujeito guineense e, por extensão, do homem africano continental.

Nesse sentido, o status quo guineense será questionado tanto pela política exterior, sob a acusação de que os guineenses não são capazes de se auto-gorvernarem, quanto pelo descontentamento das massas e pequenos grupos políticos marginalizados da Guiné-Bissau. Com isso, Filinto de Barros, por meio, sobretudo, do narrador, traz essa natureza dupla da crítica em seu livro. Kikia Matcho narra a agonia de Guiné-Bissau tendo em vista essas duas perspectivas.

Por outro lado, há um elemento na própria obra, poético e mítico, que contradiz essas narrativas. Se por um lado, a luta de libertação e a situação pós-colonial são vistas (tanto pelos "de dentro" quanto pelos "de fora") como elementos desagregadores da sociedade tradicional guineense, a inscrição da imagem do Kikia volta a lembrar e a sugerir uma refundação da civilização guineense num tempo em-se-fazendo, sob o signo da "imprevisibilidade" (GLISSANT, 2005). Contudo, a compreensão dessa imagem requer um olhar mais atento sobre as estratégias de sobrevivência cultural dos guineenses em tempos de guerra, de diásporas e de incertezas em relação ao futuro.

Parece que a sobrevivência da cultura guineense se mantém por meio de supressões, adaptações e acréscimos sem que a intelligentsia a perceba claramente. Filinto de Barros tem, entretanto, a vantagem de mostrar essa realidade. A descrição abaixo é a do templo do Irã (divindade guineense), deslocado para dentro do quarto de uma feiticeira: 
Ao lado da cama, uma quantidade de garrafas meio vazias, pedaços de pau cruzados de várias maneiras, cada uma com o seu significado. Panos de pente de cores garridas, com predomínio do vermelho cobriam parte desses pedaços de madeira. No meio dessa amálgama via-se um tronco de árvore com um manto vermelho a envolvê-lo (BARROS, 1997, p. 95).

Antes da guerra, o culto era tradicionalmente feito debaixo dos poilões (grandes árvores sagradas aos guineenses). Mas agora o ritual é feito no quarto pelo religioso e, da árvore, manteve-se apenas parte dela, um pedaço do tronco. Se antes o culto mantinha uma ligação fundamental direta com o local (terra, árvore, espírito = guineense), po meio da árvore com suas raízes no território, agora, esse mesmo culto aparece desterritorializado, podendo se deslocar de um local a outro, pois sua simbologia evoluiu, tornando mais abstrata em relação à localidade e ao indivíduo. Contudo, a ideia fundamental de pertencimento ao local ainda prevalece, mas esse local deixa de ser "puramente terra" para vislumbrar-se como "puramente imagem da terra". Uma espécie de Canaã para os cristãos, ou seja, um mito fundador da identidade religiosa de um povo.

Enfim, o rito é mantido, o que mostra a potência da cultura guineense. Por meio da manutenção da mística com o tronco do poilão, houve também uma recontextualização desse rito, ou seja, um deslocamento necessário para que a cultura guineense se mantivesse atuante e, sobretudo, como fator de identificação entre os guineenses e de diferenciação aos indivíduos pertencentes à outras culturas. Essa nova configuração do templo permite, enfim, que a cultura guineense possa se deslocar por meio dos indivíduos, sem a necessidade de clausura em seu próprio território, e permite, também, que outros indivíduos possam integrar-se a ela. Isso torna a cultura guineense transnacional e universal, o que antes não era possível.

Fora da África, os elementos do ritual dos irãs são substituídos por elementos locais: "Na falta, algum material local servia. Para cimola, em vez de citi cu liti, 'N Malé propunha arroz com iogurte” (BARROS, 1997, p. 145). Assim, a personagem Joana poderá entrar em contato com os irãs, bem como manter sua fé com base na religiosidade guineense, mesmo estando afastada de Guiné-Bissau. Com a importação do tronco de poilão e com a substituição de certos artefatos religiosos, a cultura guineense se reestabelece e reafirma a sua importância: "O irã de 'N Malé estava satisfeito na sua nova casa, melhor, no seu novo habitat. 
Em vez de ficar a lamentar-se dos meninos que viraram brancos, o irã de 'N Malé gostou de ter acompanhado os meninos que preferiram continuar pretos, lambendo os pratos de sopas dos brancos" (BARROS, 1997, p. 146).

Em síntese, o problema da colonização, da luta colonial e da convulsão social do pós-independência levaram os guineenses a empreender uma verdadeira batalha cultural com o único objetivo de continuarem a existir para si e para o mundo. E nesse processo, descrito por Filinto de Barros, podemos observar que a cultura guineense encontra uma nova expressão tanto dentro quanto fora do território. Com isso, mesmo diante de um cenário histórico desolador, a cultura guineense se expande e se oferece como alternativa à narrativa da nação, ou seja, como promessa ao existir. E, contrariando a expectativa de que a cultura guineense pudesse ser diluída pelo atavismo da cultura do ocidente e por deslocamentos compulsórios, presenciamos um movimento contrário na diáspora guineense. É na privação da terra que o guineense toma consciência da sua guineidade e de sua diferença em relação ao Outro. E este, então, é posto no dever moral de reconhecer a força da humanidade guineense que, por tanto tempo, foi historicamente negligenciada.

O fator de reorganização cultural guineense está na imagem do kikia matcho, indo muito além um aspecto puramente religioso. $O$ entendimento de que a coruja macho é portadora de uma mensagem e de uma lembrança do que é ser guineense reorganiza e reatualiza a condição existencial da guineidade dentro de um contexto de conflitos e disputas culturais acirrados.

Para Benaf, o kikia ("mocho" na língua portuguesa de Portugal e de Guiné-Bissau), é apenas uma coruja:

Olhou para o relógio, fechou o rádio portátil e decidiu partir, sem antes ter atirado uma pedra para afugentar um mocho - kikia, para os da terra - que teimava em poisar na janela do seu quarto. Benaf achou estranho uma ave nocturna a voar àquela hora da tarde, mas limitou-se a atirar a pedra. (BARROS, 1997, p. 13)

Podemos observar na narração acima, a dualidade e ambiguidade discursiva em torno da palavra "kikia". Em crioulo, kikia não é apenas uma ave, pois tem seu significado culturalmente deslizante. E quando se diz "kikia" e não "mocho", a língua indica a quem se dirige o termo. Para Benaf, não se trata mais de um 
"kikia". Assim, esvaziado da significação cultural, o personagem entende o vocábulo apenas na sua condição de dicionário, como um "mocho" simplesmente.

Em oposição, Joana e Papai obedecem ao imperativo do kikia, procurando reinterpretar a mensagem que receberam. A imagem do kikia funciona, em ambos, como ponto de viragem cultural no presente. O kikia reconecta a guineidade que, nesses personagens, estava posta na subalternidade. A necessidade econômica, em Joana, e a ideologia política, em Papai, os fizeram se distanciar da própria tradição. Porém, a retomada da tradição não ocorre da mesma forma como no passado. No "toca tchor" - cerimônia fúnebre guineense - a alma do difundo não se desprende do corpo até terminar o ritual. Com o kikia aparecendo para Benaf, Papai e Joana, a alma de 'N Dingui quebra o protocolo do rito fúnebre, mas mantém vivo o imaginário da cultura guineense. Com isso, toda a dimensão transcendental da identidade guineense faz-se presente, recuperando a centralidade da cultura para dizer o passado, o presente e o futuro.

Depois de situar o ambiente com uma multidão de "kassisas" - próximo daquilo que vulgarmente chamamos de "almas penadas" -, misturados, portanto, ao mundo dos vivos, Filinto de Barros obriga o leitor a adotar a perspectiva guineense para compreender a situação descrita no livro. E, a partir desse foco, a narrativa se desdobra, abrindo caminho para conclusões diversas. Assim, percebemos uma encruzilhada na contemporaneidade guineense, onde, pelo menos, dois roteiros são postos em evidência: a) viver à sombra dos mortos, ou seja, no necrotério da cultura tradicional guineense, dilacerada pela colonização, pela luta independentista e pelo vazio pós-colonial ou b) reimaginar, reconduzir e reabilitar a cultura tradicional guineense em outras bases, no sentido de que ela possa perseverar como uma força do imaginário guineense capaz de resistir às pressões, às instabilidades e às submissões das mais diversas, mesmo que tenha que, para isso, fazer concessões e adaptações nada consensuais. A nosso ver, esse dilema (enigma) da cultura guineense, magistralmente descrito por Filinto de Barros, continua aberto, à espera de uma resposta. 


\section{Referências}

AUGEL, Moema Parente. A nova literatura da Guiné-Bissau. Bissau: INEP- Instituto Nacional de Estudos e Pesquisa, 1998.

BARROS, Filinto de. Kikia Matcho. Bissau: Instituto Camões/Centro Cultural Português de Bissau, 1997.

. Kikia Matcho. O desalento do combatente. Lisboa: Caminho, 1999.

BHABHA, Homi. O local da cultura. Trad. Myriam Ávila; Eliana Lourenço de Lima Reis; Gláucia Renate Gonçalves. Belo Horizonte: Ed. UFMG, 1998.

DELEUZE, Gilles; GUATTARI, Félix Mil platôs: Capitalismo e esquizofrenia. Trad.: Aurélio Guerra Neto; Célia Pinto Costa. Rio de Janeiro: Ed. 34, 1995, vol. I.

FANON, Franz. Peles negras, máscaras brancas. Salvador: Editora EDUFBA, 2008.

GLISSANT, Édouard. Introdução a uma poética da diversidade. Trad.: Enilce A. Rocha. Juiz de Fora: Editora UFJF, 2005.

GLISSANT, Édouard. Poética da relação. Porto: Porto Editora, 2011.

HAMILTON, Russel G. Literatura dos PALOP e a teoria pós-colonial. Via Atlântica, São Paulo, n. 3, p. 12-22, 1999.

PROPP, Vladimir. Morfologia do conto maravilhoso. Rio de Janeiro: Forense Universitária, 2006.

SAID, Edward. Orientalismo: o Oriente como invenção do Ocidente. Nova edição. Trad.: Rosaura Eichenberg. São Paulo: Companhia das Letras, 2007.

SOUZA, Lynn Mario T. Menezes de. Hibridismo e tradução cultural em Bhabha. In: JUNIOR, Benjamin Abdala (org). Margens da cultura: mestiçagem, hibridismo \& outras misturas. São Paulo: Boitempo, p. 113-133, 2004. 